\title{
Cruise tourism as a factor of sustainable development of the territories of the Russian Federation
}

\author{
Nadezhda Agaeva ${ }^{1, *}$, Irina Shchetilina ${ }^{1}$ and Elena Kovaleva ${ }^{1}$ \\ ${ }^{1}$ Voronezh State University of Engineering Technologies, Voronezh, Voronezh Region, Russia
}

\begin{abstract}
At the present stage, the Russian Federation is at a fundamentally new stage of socio-economic development, a clear manifestation of which is expressed in the growth of economic recovery indicators, an increase in investment potential, a reorientation to domestic producers and domestic products. In this connection, the tourism sector can act as a serious tool for the socio-economic development of the Russian Federation. Tourism has a significant impact on ensuring sustainable socioeconomic development. Tourism, developing at a rapid pace, contributes to the development of related industries. The development of the tourism sector should proceed along the path of sustainable development of the constituent entities of the Russian Federation, and is aimed at removing infrastructural restrictions for the full use of the potential of the territories of Russia. In order to identify internal unused natural reserves, preserving the uniqueness and ensuring the environmental safety of the territories of advanced development. In this connection, it is advisable to use the cluster approach to clearly define the strategic territories for the development of the tourism sector. A "tourist cluster" is a collection of enterprises assembled into a single, logically structured system. They provide development, production, promotion of a tourist product. At the same time, one of the main guidelines for the development of the tourism sector is the provision of world quality standards.
\end{abstract}

\section{Introduction}

At the present stage and in recent decades, great attention is paid to the development of the tourism sector. Especially, if we take into account the possible financial benefits from the development and functioning of this sphere, then we can assume that the tourism sector in all its directions is extremely promising for development on the territory of the Russian Federation. Possessing unique natural resources, huge territorial and water bodies, the tourism sector can catch up with oil production in terms of profitability, and not only that. At the present time, a wide list of key regulatory documents has been developed and put into effect, aimed at the development of tourism in general and its highlighted areas, in

\footnotetext{
*Corresponding author: Nadinn ktn@ mail.ru
} 
particular, cultural and educational tourism, children's tourism, hiking, ski tourism, cruise tourism, ecological tourism, business tourism.

\section{Methods and methodology}

In the work, empirical methods (description, comparison, modelling), general logical methods (analysis, synthesis, generalization, analogy), methods of economic analysis (expert assessments) were used as methods of scientific research.

\section{Research results}

Analyzing current trends in the development of tourism in the external and internal markets, it is possible to determine the urgent need to increase the competitive advantages of the national tourism product, which can be further sold on the international market, and as a result, to use the created competitive product in order to attract investment to the Russian market [1].

To create a competitive tourism product, it is necessary to identify the range of its main characteristics, namely: the target audience, the expectations of the target audience from the tourist product, which directly form the potential of the product, highlight the most promising territories used for the development of the tourist product, ensure broad participation and interest of business, showing them the integrated development of the tourism sector.

Naturally, investment from business is excellent, but first of all, it is necessary to form resource and financial support from the state for the advanced development of the allocated territories that have the necessary natural potential for the development of tourist areas, improve their investment potential in order to attract business partners and create positive conditions for investment in the sphere of tourism. Undoubtedly, an integrated, systematic approach to the development of territories is implemented through the formation of plans for the development of tourist territories, and overall coordination is carried out by regulatory documents of strategic and territorial planning, as well as various programs aimed at socio-economic development.

Improving and increasing the investment potential of the above territories, possibly through the use of special sequential methods for the development of territories, changes in tax burdens, the development of programs for concessional lending of land leased for the construction or modernization of various types of accommodation facilities and tourism facilities, the provision of financial support from the state in promoting facilities tourist display and in the development of the infrastructural component of tourist facilities.

All of the above points can be considered as the main directions of tourism development and the creation of a competitive tourism product. Moreover, it should be noted that the competitiveness of a tourist product of different levels is formed with the aim of creating the most positive perception of a tourist. These directions are the basis for an integrated approach to the development of the tourism sector, and it should be based on the most positive perception of the tourist about the trip, starting from its idea, and ending with its arrival home. The competitiveness of a tourist product is a very capacious concept, which includes the qualitative characteristics of the availability of transport infrastructure, the infrastructure of tourism itself and tourist infrastructure, the quality of service, the popularization of the brand of the country or a specific tourist destination.

Speaking of the Russian Federation, the formation and development of a competitive Russian product, it should be noted the need for the formation of a brand that has tourist attractiveness and recognition, improving the quality of the provision of tourist services, 
and improving the availability of services for foreign tourists. Improving the quality of the provision of services will entail a change and rapid development of tourism infrastructure, increase the level of training of specialists for the tourism sector, enhance the integrated safety of the tourism product, and create conditions for the development of small and medium-sized businesses, which will lead to close interaction between business representatives and regional authorities. This interaction will contribute to joint planning for improving the territories for their further development, the systematic introduction of the best service standards, the introduction of quality systems, thereby contributing to the development of a competitive market for the provision of tourism services.

Speaking about tourism itself, we can say that most of its types have specific directions, in particular, health improvement, treatment, the study of recreation, cognitive, sports, business, religious and others, and people who make such trips do not engage in the main type of activity that brings income - this is the concept of tourism. Moreover, exploring the features of each of the types, being in close interconnection of multi-level programs aimed at the development of the sphere as a whole, it is possible to develop an integrated development of tourist activities. Now, one of the main documents ensuring the development of the tourism sector is the program for the development of federal significance for 2019-2025. Analyzing the main directions of tourism indicated in the program, one can notice that special attention is paid to cruise tourism in Russia, in general. Cruise tourism has been in the area of special attention of the Government of the Russian Federation since 2016, and to this day, this direction does not lose its relevance.

Cruise tourism is very specific, based on this; several specific features can be distinguished. This is shown in figure 1.

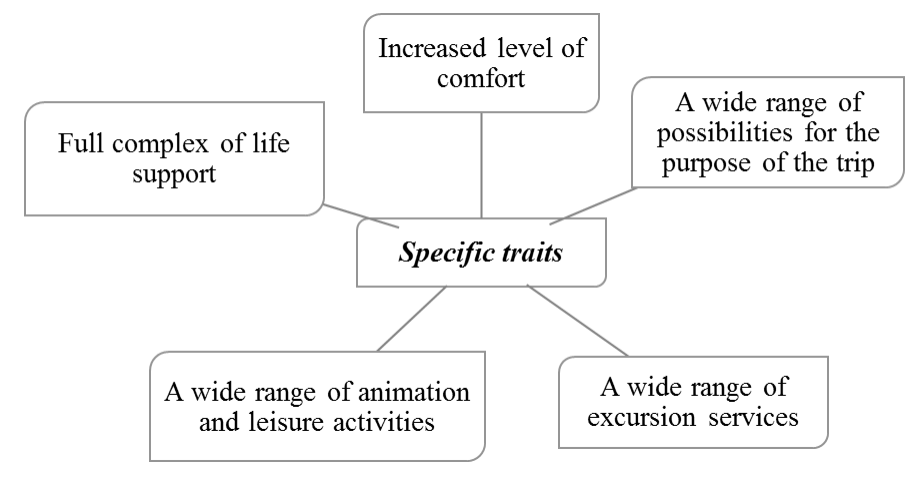

Fig. 1. Specific features of cruise tourism.

Based on the outlined specifics, we can conclude about the functional features of a cruise liner that it should have. This is shown in figure 2. 


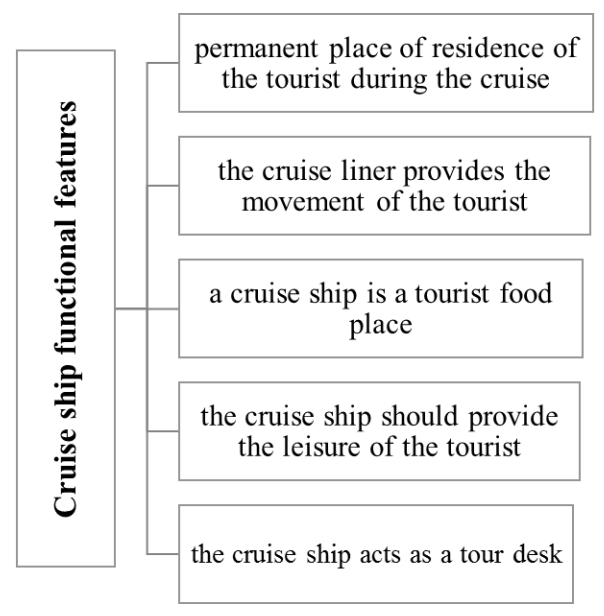

Fig. 2. Functional features of the cruise ship.

One of the features of the cruise is its wide geography, which facilitates acquaintance with the sights of the city of the countries through which the liner travels.

Cruise liners are characterized by a well-developed infrastructure of the ship; therefore, having a very modest territory, they can provide a wide range of services.

Assessing the modern market of tourist services, we can say that society is developing dynamically, and its change certainly requires a quick response to meet the needs of tourists. New types of tourism are appearing on the market. Cruise tourism is one of the most promising directions today. Analyzing the profitability of the population in more developed countries, we can conclude that in connection with the demand of tourists, the cruise tourism market is increasing, which in turn leads to an increase in supply and contributes to the expansion of social groups. At the present stage, even the budgetary segments of the population have the opportunity to take advantage of the offer of buying a cruise, choosing a cruise at their own income.

Speaking about the cruise potential of Russia, we can say that it is one of the most promising countries for the development of cruises, which has huge water resources. The climate and geography of the Russian Federation are very individual. Due to its very large territory, Russia has several climatic zones; in addition, the waters of four seas, having the longest coastline, wash it. These facts clearly indicate the need to develop cruise tourism and the likelihood that Russia can become the leader in the provision of cruise products.

According to analytical agencies, annual growth in demand is predicted, as evidenced by the growing interest of both Russian and foreign citizens. However, it should be noted that only 30 out of 90 available cruise liners in Russia accept foreign tourists. Most of them are targeted at the local population.

In the Russian Federation, there are several directions that are most promising for the development of cruise tourism. These are Baltika, Sakhalin, Vladivostok. Moreover, in addition to meeting the needs of tourists, there is an expansion of trade routes, the establishment of business routes, which ensures the sustainable development of the country and interethnic relations, and also contributes to strengthening the image on the world stage.

Speaking about Vladivostok, one cannot yet boast of serious successes and large profits in the regional economy. This is explained by low investment activity and the transition of the market to a new quality of service provision. The quality of the cruise product at the present stage is severely lame. There are no ships, no well-designed routes, no information and advertising campaigns, which essentially forces local tourists to use the products of foreign campaigns. Accordingly, the study of the potential of cruise tourism, as a factor of 
development and sustainability, it is advisable to start from the Primorsky Territory. In addition, these territories are zones of special socio-economic development and contribute to the formation of a positive image of the country in the world market. The Primorsky Territory has great potential, and has recently been of strategic importance in terms of forming a tourist zone, as well as establishing business contacts with the Asia-Pacific region, through the fact that it has extensive sea borders and borders China and the People's Democratic Republic of China [2].

Primorye is a territory of unique natural resources, beauty and vast water resources, which undoubtedly attracts tourists. At this stage, this is one of the most remote corners of Russia, where extreme types of recreation, hiking routes, paragliding are developed. A large number of routes are implemented by land and by comfortable boats. The Primorsky Territory is very attractive for the formation of a tourist cruise tourism zone. This is facilitated by the fact that the largest city is located here - a port in the Far East, which has unique natural, cultural and historical resources. The emerging cruise offerings have a wide geography. Very often routes originate in the East Asian region. The popularity of such routes is growing very quickly, and this is due to the fact that in one trip you can visit countries with different cultures [3].

Based on this, it can be noted that Primorye has a lot of advantages over other regions of Russia. The basis for the development of unique cruise routes to the Primorsky Territory by sea can be attributed to:

- Developed infrastructure,

- Unique natural resources,

- Objects of tourist display,

- The largest seaport.

We can say that Vladivostok is a special economic, tourist and recreational zone of advanced development, as well as the economic and technological center of the Russian Federation. Moreover, the President of the Russian Federation V.V. Putin noted the urgent need to pay special attention to such territories. In particular, speaking about Vladivostok, the President proposed to recapitalize the fund now and grant it the status of a free port, which can help improve the investment activity of the city [4].

Taking into account the special geographical position, the uniqueness of the natural resources of Primorye, the importance from a geopolitical point of view, as well as the increasing role of the Asia-Pacific region, it is necessary to develop separate approaches to form the tourist attraction of the region.

When forming cruises, the following aspects are important:

- Well-developed port infrastructure,

- Long coastline,

- Proximity to developed countries.

\section{Discussion of the results}

Citing the statistics for 2019, the following points should be highlighted. This year has been extremely productive for the city. The season lasted just over 6 months. About ten vessels were accepted, which made 17 calls. The well-known ships Costa Neo Romantica and Costa Serena, Ocean Dream and Diamond Princess have entered the port. You can also boast of the "newbies" Dutch Maasdam and Westerdam. The biggest achievement of the year is the entry of Royal Caribbean's large vessels Spectrum of the Seas and Quantum of the Seas, which are the largest vessels ever to enter Russia. In comparison with the year 2018, the number of ship calls has tripled. Tourist flow from cruise tours has doubled. A separate plus is the fact that ships of a higher level arrive in the city. Passenger traffic from 
cruise trips at this stage is very small, about $5 \%$ of the total tourist traffic, but the potential is very large, which indicates the growth opportunities for cruise tourism [5].

For a very long period, the issue of deepening the bottom in Vladivostok was acute. Many giant liners considered entering Vladivostok, but the depth of the quay wall did not allow this. Now this issue has been resolved and the berth has the ability to simultaneously receive two vessels with a capacity of up to 2.5 thousand people. As a result of the full load of the Vladivostok port, it is planned to build a passenger terminal on Russky Island [5].

Primorye possesses a number of national parks, reserves, medical and recreational areas. There are more than 2000 thousand monuments of historical, cultural, architectural, monumental and archaeological significance in the region. Currently, the city can already offer objects of tourist display - this is the infrastructure created for the 2012 summit. The most significant of them are the Opera and Ballet Theater, the Oceanarium (one of the largest in the world), the Primorye play area. The main advantages of these objects are that they meet the world level and they can be visited a large number of times [6].

According to experts, the main obstacle to the development of cruise tourism is the undeveloped infrastructure of Vladivostok. In the very near future, it is necessary for the city to give the appearance of a modern city of port significance, especially in the conditions that Vladivostok will become the starting point of cruises and the host country.

Formation of the tourism sector and increasing its competitiveness in the international market contributes to solving many problems of the Far East:

- Stable investment flow,

- Creating opportunities for businesses and local residents,

- An increase in trade volumes with the countries of the Asia-Pacific region,

- Support and development of indigenous peoples,

- Ensuring environmental safety and environmental protection.

Investments are needed to carry out all of Russia's ambitious plans. It is necessary to show foreign investors that the tourism industry has a massive development. This can be done through international events aimed at popularizing the country's capabilities. In particular, the International Tourism Forum, which is held annually in Vladivostok, has already become the basis for promoting tourism projects [5].

Based on the program for the development of tourism until 2025, several promising investment projects in the Far East can be identified, showing the maximum investment capacity and attractiveness for foreign tourists: Amur, Primorye, Kamchatka, the main specialization of which, the priority type of tourism, is cruise tourism. Within the framework of the target program, all projects will receive state support $[7,8,9]$.

\section{Conclusion}

So, speaking about the coastal regions of the Far East, we can say the following:

- Primorsky Krai - shows a record number of cruise ships,

- Sakhalin - received three large foreign vessels,

- Kamchatka - organizes expeditionary tours along the Northern Sea Route,

- Magadan Region - organizes tourist infrastructure on the Nagaev Bay.

The development of the port of Vladivostok made it possible to increase the entry of vessels with increased passenger traffic. The tourist flow of Kamchatka in the last three years has also shown a steady growth - about 20 accepted vessels, carried out through the reconstruction of berthing facilities, as well as the development of new Arctic programs. Sakhalin also shows sustainable development at the level of expedition tours from Japan, Korea and the USA [10,11].

In 2018, an agreement on the development of cruise tourism was signed at the EEF. The main idea of which is the development of a Far Eastern cruise line, the first Russian route. 
Also, in the document signed at the EEF, it is said about the promotion of the interregional cruise brand Pacific Russia, and the inclusion of all four entities in the cruise operators' route will actually create the "Eastern Ring of Russia".

Thus, the creation of a Far Eastern cruise line will contribute to the development of the hospitality sector, the creation of new jobs, the creation of points of contact for international cooperation, the improvement of investment potential and the attraction of foreign investment. Of course, line efficiency is directly proportional to passenger traffic. Forming a niche for the development of cruise tourism, it is necessary to thoroughly approach this issue. The development prospects are very high and already in the early stages show their efficiency and sustainable growth.

\section{References}

1. B.E. Nikitin, M.N. Ivliev, Yu.V. Bugaev, E.N. Kovaleva, S.V. Chikunov, V.A. Negoda, RuDEcK, 495 (2020)

2. Federal Agency for Tourism: Primorsky Krai - Text: electronic, Tourimz in Russia, URL: https://www.russiatourism.ru/regions/?freg= 257 (2021)

3. Tourist attractiveness of Primorsky Krai, Electronic resource URL: http://assoc.khv.gov.ru/regions/economic-activities/tourism-recreation/vkr/46 (

4. N.Yu. Agaeva, T.V. Alekseeva, E.S. Taltynova, A.E. Stolyarov, D.M. Pevneva, I.P. Nesterenko, Bull. VSUET, 1 (83), 313(2020)

5. More foreign liners and a domestic route. How cruise tourism is developing in the Far Eastern Federal District, https://news.rambler.ru/other/43384546-bolshe-inostrannyhlaynerov-i-otechestvennyy-marshrut-kak-v-dfo-razvivaetsya-kruiznyy -turizm

6. Concept of the Federal Target Program "Development of domestic and inbound tourism in the Russian Federation (2019 - 2025)", http://static.government.ru/media/files/FoFftF1dhGs4GZzEBPQtLCFVtB12hHQD.pdf

7. H. Zabihi, M. Alizadeh, ID Wolf, M. Karami, A. Ahmad, H. Salamian, A case study of Babol in Iran (2020)

8. C. D'Souza, M. Taghian, T. Marjoribanks, Tourism recreation research, 44(4), 533 (2019)

9. T. Cheng, C. Wu, J. Wang, Current issues in tourism. 22(14), 1764 (2019).

10. H. Tan, W. Zhu, Euro-Asian Conference on Corporate Social Responsibility (CSR) and Environmental Management - Tourism, Society and Education Session (Part III), (2018) 